Yu.V. Batygin, E.A. Chaplygin, S.A. Shinderuk, V.A. Strelnikova

\title{
THE MAIN INVENTIONS FOR TECHNOLOGIES OF THE MAGNETIC-PULSED ATTRACTION OF THE SHEET METALS. A BRIEF REVIEW
}

\begin{abstract}
Purpose. The description of the Equipment for the Magnetic-Pulsed Attraction (or EMF-attraction) of the sheet metals which allows non-contact deforming of ferromagnetics (the low carbon steels, for example), the non-magnetic billets from aluminium alloys and the practical realization of the new advanced technologies in the modern processing manufacture. Methodology. Comparative analysis of characteristics and operating conditions of the systems under consideration. Results. Physically, all magnetic-pulsed methods of attraction are based on the Lorentz repelling forces decreasing and on increasing the attracting forces when the sheet billets being deformed are transparent for the low working frequency acting electromagnetic fields. The ferromagnetic samples attraction is caused by their magnetic properties. For the non-magnetic metals attraction an accessory conducting screen is being introduced in construction of the inductor system which is the method tool. In this case the attraction effect is caused by the force interaction of the unidirectional currents induced in the screen and in sheet billet. The different constructions of the attracting tools attended for fulfilling the different production operations (for example, it can be stamping, flattening etc.) with metals owning by different electrophysical properties are represented. Originality. The novelties in the magnetic pulsed installations used as the power sources in the complex equipment for the automobile bodies repair are given. Practical value. The practical application of the elaborated systems for the dents removing in the sheet metals are suggested and successfully approbated. In the whole these works can be considered as new scientific direction and used for different manufacturing aims though the main attention is paid to the practical application in the field of the automobile bodies repair. The most part of the described inventions is defended by the Ukrainian Patents (23 from total quantity - 33 References) and little known to the west specialists in the area of the magnetic pulsed technologies. From the authors view point this is a main particularity and usefulness of the present paper. References 33, figures 11.
\end{abstract}

Key words: magnetic-pulse metal working, electromagnetic forming, electromagnetic attractive forces, ferromagnetic materials, non-magnetic metals, low frequency discharges.

В статье описано оборудование, предназначенное для магнитно-импульсного притяжсения листовых металлов, которое позволяет бесконтактное деформирование, как ферромагнетиков, так и немагнитных заготовок из алюминиевых силавов и практического применения новых передовых технологий в современной индустрии. Притяэение ферромагнитных образцов обусловлено их магнитными свойствами. Для притяжения немагнитных металлов в конструкцию индукторной системы, являющейся инструментом метода, вводится вспомогательный проводящий экран. Представлены различные конструкции инструментов притяжения для выполнения различных производственных операций по обработке металлов, обладающцх различными электрофизическими свойствами. Описана новизна магнитно-импульсных установок, используемых в качестве источников энергии в комплексах оборудовании для ремонта автомобильных кузовов. Библ. 33 , рис. 11.

Ключевые слова: магнитно-импульсная обработка металлов, электромагнитная формовка, электромагнитные силы притяжения, ферромагнитные металлы, немагнитные металлы, низкочастотные разряды.

Introduction. The Magnetic-Pulse Metal Working (the abbreviation - MPMW, the other known title is Electromagnetic Forming, the abbreviation - EMF) is a field of the Mechanical Engineering using an impulse or high speed forming technologies united by general principle of action the essence of which consists in the force action of the pulsed electromagnetic fields on the conducting workpieces. In the recent very detailed review [1] provided a development historical perspective of the MPMW traditional technologies and highlighted the state of the art on modeling, coil design, sheet metal forming, tube forming, crimping, welding, cutting, spring-back calibration and hybrid processes including the Magnetic-Pulsed Methods. Besides it was marked that good electrical conductivity of the work-pieces metal is the major requirement for the traditional MPMW to be efficient. Practically, the last remark means using rather high frequencies of the acting electromagnetic fields. All applications discussed by [1] are based on repelling so named Lorentz forces between the EMF-tool and conductive blank. In such configuration, the tool and other accessories (forming die, mandrel to which the blank is welded or crimped, shearing edge which is cutting the blank) are positioned from opposite sides of the blank. But there is another configuration of the EMF processes where the blank is attracted to the tool working surface. This is the new both scientific and practical development direction the modern Magnetic-Pulse Metal Working.
The goal of the paper is the description of the main inventions and the according technology operations in the field of the Magnetic Pulsed Attraction of the sheet metals which can be realized for different manufacturing aims though the main attention is paid to the practical application in the field of the automobile bodies repair. Concretely this is an external non-contact removal of the dents on their surfaces. A main particularity of this paper consists in a wide illumination of the author's inventions in Ukraine created on a base of the great practical experience and little known to the west specialists in this area of the magnetic pulsed technologies. These inventions defended by the national patents are evidence not only of advancement in the marked new direction of the modern MPMW. They open the real possible ways for creation of the progressive industrial technologies in the present and probably in a future.

The attraction under superposition of the high and low frequency electromagnetic processes. Chronologically, this review should be started from the first fundamental suggestion by the metals electromagnetic attraction which was formulated in the middle of the last century yet. In 1965 H.P. Furth patented the EMF process with the multiturn coil and an additional single turn with open ends [2]. The electric discharge employed for this process was rather slow and, therefore, allowed diffusion of electromagnetic field through the blank. After the induced voltage

(C) Yu.V. Batygin, E.A. Chaplygin, S.A. Shinderuk, V.A. Strelnikova 
achieves of some determined value the additional single turn with initially opened ends will be short circuited by the electrical discharge spark what will conduct to electromagnetic field eliminating from the side of the blank facing the coil. As result, the electromagnetic pressure from the side of the blank facing the coil was absent, while the pressure from the diffused electromagnetic field to the opposite side of the blank attracted it to the coil. In fact, issuing from the modern physical conceptions the described process consists in generating two frequencies of discharge: slow and fast. The fast discharge eliminates the slow field from the side of the blank facing the coil while the slow field diffused through the thickness of the sheet metal deforms the blank. This physical principle was incorporated in a number of the next electromagnetic tool designs and configurations. So, Hansen and Hendrickson [3] suggested a method and apparatus for electromagnetically removing dents from conductive materials by introducing a slow discharge through a multiturn coil and a rapid pulse of countercurrent. In [4] introduced a system of two coils and portable pulse generator generating both repelling and pulling forces to correct both concave and convex areas of the dent. In [5] introduced a crow bar system capable of shaping the pulse comprised of the fast and slow frequencies in most favorable way for the dent removal process. The final modern construction of the electromagnetic attraction systems with two working frequencies was elaborated by engineers of American firms «Electroimpact» and «Fluxtronic» [6, 7]. Given devices (Fig. 1) are intended for the dents removing on the damaged airplanes bodies panels. Their distinguished particularity is a work in regime of many-times repeating the force actions. As inventors verify this regime is obligatory for the dent removing. Deforming the damaged panel metal is impossible under the single pulse of the force action. The practical possibilities of «Electromagnetic Dent Removers (EDR)» of «Electroimpact» and «Fluxtronic» allow successful straightening the aluminum sheets by thickness about $\sim 2 \mathrm{~mm}$. Proceeding from obvious physical evaluations the represented EDR will not be able to work with ferromagnetics. Influence of their magnetic properties will mean the fields penetration intensity decreasing and as consequence the attraction forces falling down.

Another purely theoretical concept of sheet metal attraction by the coil was introduced in 1981 by Shneerson based on sudden interruption of a single frequency discharge [8]. In this case, the diffused electromagnetic field still produces the attraction forces. Should be noted this approach is similar to the before described two-frequency methods. Shneerson's suggestion looks simpler. However, its efficiency is dependent upon how fast the discharge can be interrupted. But it is very complicated technical problem. Generalizing above conducted consideration leads to conclusion: the main disadvantages of all twofrequency suggestions consist in their very complicated technical realizing, the power electronics usage, the different temporal processes synchronization etc. As result the high price of the produced equipment has a place.

The tools of the ferromagnetics attraction by the low frequency electromagnetic fields. The concept of a sheet metal single frequency attraction was introduced in $[9,10]$ for ferromagnetic materials.

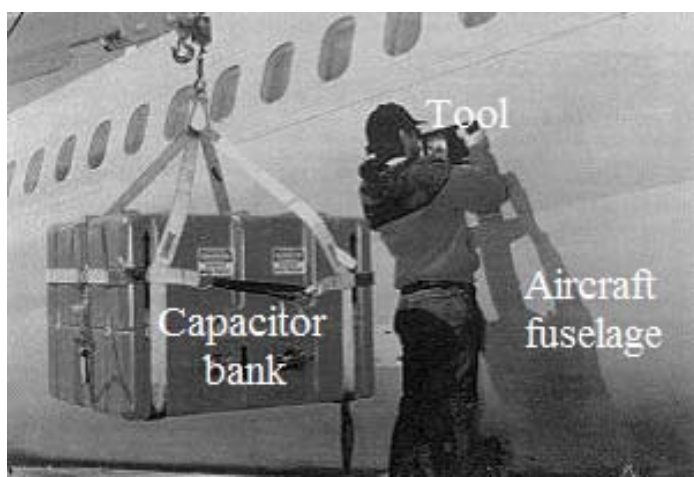

$a$

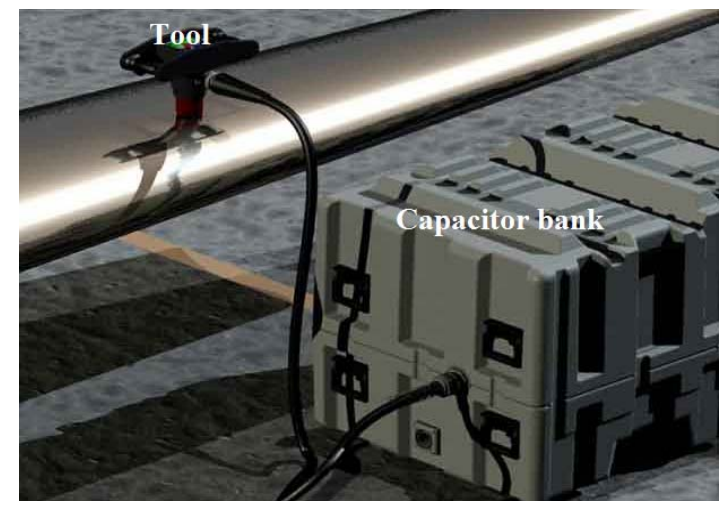

$b$

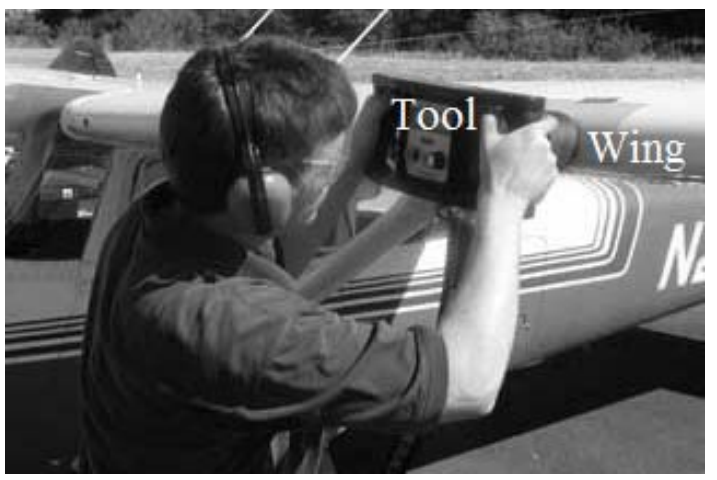

$c$

Fig. 1. The equipment and realization of the technological processes: $a$ ) the technology of «Electroimpact»; $b$ ) the equipment of «Fluxtronic»; $c$ ) the technology of «Fluxtronic»

This concept was discovered during EMF experiments with thin steel sheet plates deformed by electric discharges with different frequencies. The suggested concept quickly found its practical application in dent removal devices in automotive bodies where majority of exterior panels are fabricated from low carbon steel. The discovered phenomenon was laid in a base of [11]. The identical Patent Application was given in [12]. They have represented the specific coil designs as well as practical aspects of dent removal in automotive panels. Here should be added that Concern «Betaginnovation» by the representatives of which are the mentioned above applicants of patents have represented the technical complex titled as «Magnetic Dent Remover (MDR)»[13]. The single frequency experiments initially discussed in [14] indicated that the direction of the electromagnetic pressure for ferromagnetic steel sheet metal blanks is a function of the frequency of the discharge. At some limit, the applied electromagnetic force was changing its direction. 
For high frequencies repelling took place, but for low frequencies attraction was watched at. Formally, the acceptable low frequencies diapason had been fixed in [9] and in [10] to the ferromagnetics attraction:

$$
\omega<<\frac{1}{\mu \cdot \gamma \cdot d^{2}}
$$

where $\omega=2 \pi \cdot f$ - the working frequency, $\mu$ - the permeability of metal, $\gamma$ - electrical conductivity of sheet metal, and $d$-sheet metal thickness.

It should explain that formula (1) provides only the upper limit of the frequency where attraction can be expected. The actual boundary frequency between attraction and repelling can be order of magnitude lower. Physically, formula (1) can be further interpreted in the following way: it compares the sheet metal thickness with the skin-layer value for the given frequency. After not complicated transforming the inequality (1) can be represented in a view:

$$
\frac{d}{\Delta}<<\frac{1}{\sqrt{2}}
$$

where $\Delta=\sqrt{\frac{2}{\omega \cdot \mu \cdot \gamma}}$ - the skin-layer value or by other definition $\Delta-$ this is the so named effective depth of the electromagnetic field penetration with the frequency $-\omega$ in environment with the permeability $-\mu$ and the electrical conductivity $-\gamma$.

From a physical view point the formulas (1) and (2) give an approximate notion, what part of the magnetic field's energy remaining in the work-piece goes on excitation of the eddy currents and the Lorentz forces but without taking into account any influence of the magnetic attraction forces. Actually, the formulas (1) and (2) illustrate the approximate conditions when the Lorentz forces integral action is negligible small and the attraction is possible. Often, their fulfilling is quite enough for the necessary engineer evaluations. On principle, workability of the for first time suggested way of the ferromagnetic sheet billets attraction showed in [10] is based on three fundamental statements. The first of them consists in suppressing the natural Lorenz repelling forces. The second one this is excitation of the attraction forces caused by the sheet billets magnetic properties influence. The final third statement consists in the conditions creation when the attraction magnetic forces are prevailing over the repelling Lorenz forces. In the total, three above formulated statements provide the ferromagnetic sheets attraction by the low frequency electromagnetic fields. For effectiveness increasing the patented inductor system as the tool for the ferromagnetic sheet attraction consists of two main components as a rule. This is the single turn inductor (separately it is shown on Fig. $2, d)$ and the matching transformer $[14,15]$. By the physical essence the last one this is the usual impulse air transformer. It can have two different constructions. The first of them has a multi turn primary winding on an external surface of an inner hollow lengthy metallic cylinder (with longitudinal cut) playing a role of the secondary winding. The external primary winding is connected to the power source. The inner secondary winding is loaded by the single turn inductor. Such construction type got name «the cylindrical matching transformer» (it is shown on Fig. 2, $a$ and Fig. 2,c on the left side) [14]. The other type of the matching transformer has a multi
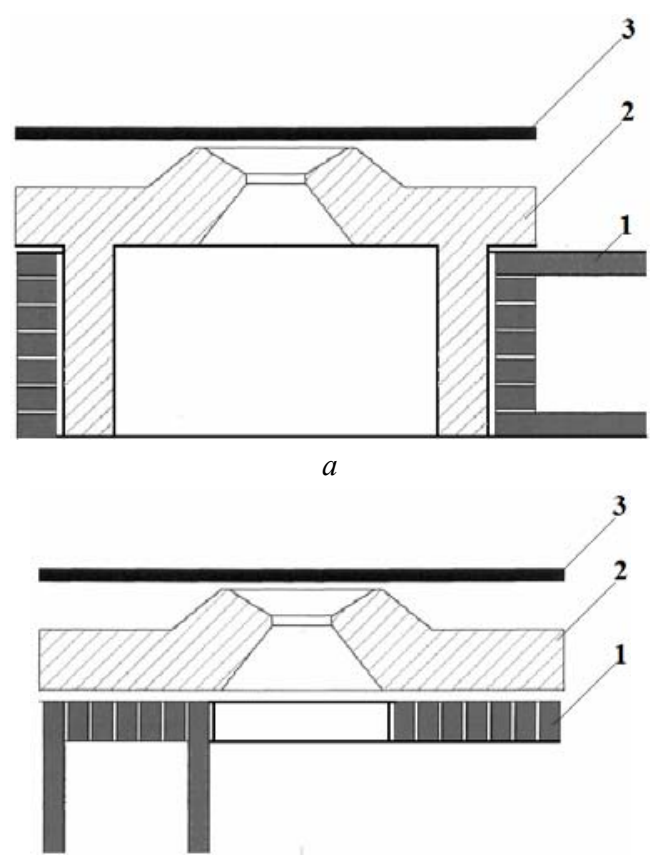

$b$

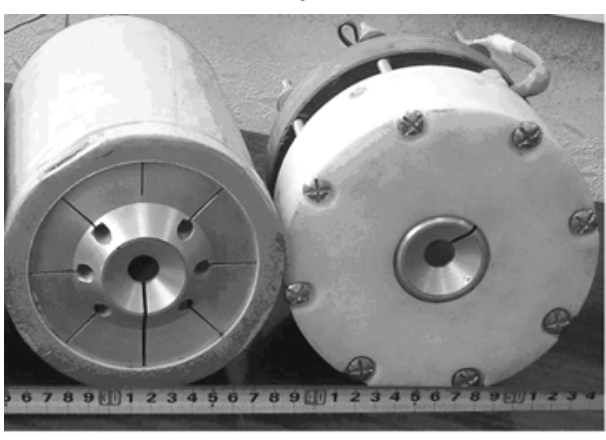

$c$

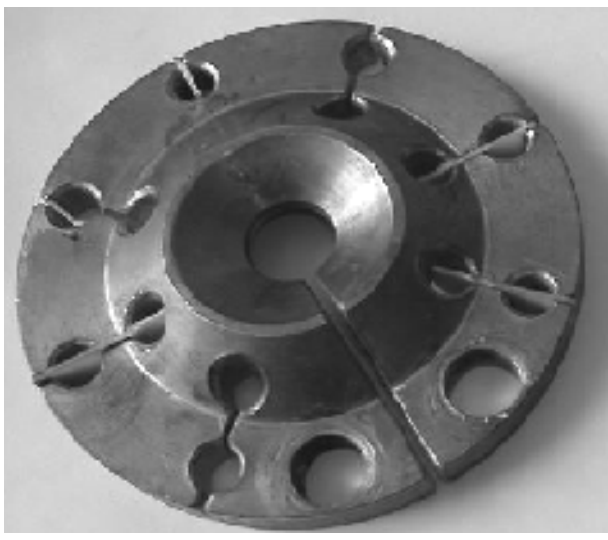

$d$

Fig. 2. The matching transformers of different constructive fulfilling, $a$ ) a principle scheme of the «the matching cylindrical transformer», $b$ ) a principle scheme of the «the matching disk transformer», 1 - the primary winding, 2 - the single turn inductor, 3 - the sheet billet; $c$ ) the cylindrical and disk constructions

photos; $d$ ) a single turn inductor with the conical inner bore

turn flat spiral winding placing through isolating insert on a flat surface of the single turn inductor. Such construction type got a name «the matching disk transformer» (it is shown on Fig. 2, $b$ and Fig. 2,c on the right side) [15]. The appointment of the matching transformer consists in the inductor current increasing under preserving the electromagnetic energy from the power source. 
Concerning the matching disk transformers the last useful remark. The primary winding is being experienced the great electrodynamical efforts repelling it from the massive single turn of the secondary winding. Their action weakens electromagnetic connection between windings, decrease current in the single turn inductor and as consequence decrease the attraction efforts. Eventually, the repelling forces destroy the primary winding coil. In order to avoid these negative effects some damping device can be installed. Two according solutions were suggested and patented [16]. The first one this is application of a damping elastic insert between the primary winding external surface and upper cover of the disk transformer body. The second solution supposes installation of the additional massive conducting screen on the primary winding external surface. In this case the excited repelling forces will act as from the side of the single turn inductor as from the side of the additional screen. Choosing its parameters the result as a sum of two oppositely directed forces will allow unloading the disc transformer primary winding. The elaborated tools for the ferromagnetics attraction were tested in a special experiment with the different sheet steel specimens. A first part of the conducted experiment consisted in creating two convexities on the smooth surface of plates with thickness $\sim 0.008 \mathrm{~m}$ by the magnetic-pulsed attraction. One of them will be object for further removing but already as a dent and second will stay for comparison. Both convexities had the half-spherical shape with diameter approximately about $\sim 0.015 \mathrm{~m}$ and depth about $~$ $0.002 \mathrm{~m}$. In the experiment next part the plates were being turned over. The plates were placed on the flat insulated surface of inductor so that one of the dents turned out opposite the inductor inner hole. The dent removing was made by the magnetic-pulsed attraction. After the five times force action this dent was disappeared practically.

The surface of the sheet, where it was, had been becoming quite smooth. It should be noted the quite interesting circumstance here. The subsequent magnetic-pulsed attraction could lead to appearance of a new dent with opposite curvature in relation to the initial one. So this experiment demonstrated a possibility of the controlled deforming demanded part of the sheet metal. One of the experimental specimens with initial and removed dents is shown below on Fig. 3.

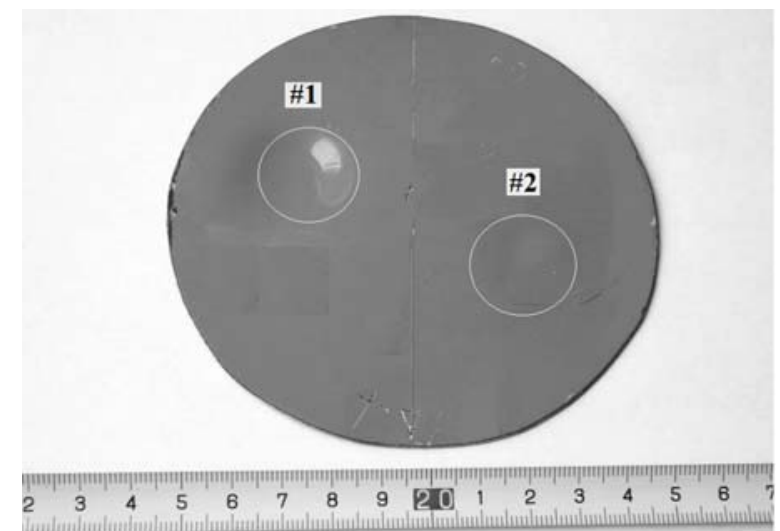

Fig. 3. The experimental specimen from the sheet steel of the body car «Mitsubishi»: \#1 - the dent got by the magnetic-pulsed attraction on the sheet assigned part, \#2 - the sheet surface part with the removed dent
The low frequency electromagnetic tools of the nonmagnetic metals attraction. For a better understanding it should start from the main statements providing operability of the patented way for the non-magnetic metals magneticpulsed attraction [17] in comparison of the previous consideration for ferromagnetics [10]. As before the first statement consists in suppressing the natural Lorenz's repelling forces. As before this problem can be solved by work in the low frequency temporal regime (formulas (1) - (2)). The second statement about workability consists in the attracting forces excitation. In the previous consideration these were the forces conditioned by the magnetic properties of the ferromagnetic which is being deformed. The suggested way for non-magnetic metals believes application of the known Ampere's Law according to which the unidirectional currents experience the mutual electrodynamical attraction. For practical realization of this suggestion it is necessary introducing an auxiliary screen into the inductor system construction. This additional constructive element has to be placed parallel to surface of the sheet which is being deformed. The currents induced in metal of the screen and of the sheet billet will experience the mutual attraction. The electrodynamical attraction tool of the described action principle was named as «Inductor System with Attracting Screen (ISAS)». The constructive particularity of the ISAS first variant consisted in what the single-turn inductor was located between the sheet metal blank and the accessory attracting screen [17]. The photograph of this construction intended for the model experiments is shown on Fig. 4. The visual notion about physical picture of the occurring processes can be got from the scheme on Fig. 4.

As it is seen from Fig. 4 in the inner space between the screen and the billet the intensities of magnetic fields $\left(\mathrm{H}_{\tau 1,2}\right)$ which are being excited by the unidirectional induced currents $\left(\mathrm{J}_{1,2}\right)$ are directed oppositely. They are being subtracted from each other. The resultant magnetic intensity will be decreasing and in an idealized case it will be tending to zero. Outside of the system the excited magnetic field intensities have the same directions. They are being summed. The resultant intensity of the external magnetic fields will grow and tend to doubled value of the field intensity excited separately by each from the induced currents (an idealized case). Thus, the inner magnetic field is falling down but the external field is growing. As consequence the magnetic pressure from outside will be a reason of the sheet billet attraction to the fixed screen. Quite conventionally, the corresponding stressed state of the inductor system conditioned by Ampere's attraction forces can be defined as its «compression». But besides of the attraction forces corresponding to Ampere's Law the Lorentz repelling forces are being excited as well. Their action is conditioned by summing the magnetic fields intensities of the induced currents and the inductor current in the inner space and subtracting these intensities in outside the inductor system. So, the Lorentz's forces acting on the screen and sheet billet from inside will exceed the forces acting in outside. Quite conventionally, the corresponding stressed state of the inductor system conditioned by Lorentz's repelling forces can be defined as its «expansion». In integral, if «compression» prevails over «expansion» the represented ISAS will work as the attraction tool of the sheet blanks from metals of any electrophysical nature (as from ferromagnetics as from non-ferromagnetics). In whole all 
further cited Patents ISAS are dedicated to their effectiveness increasing. As a rule with this goal some constructive components are being introduced and modified. But presence of the base elements such as low working frequencies (inequalities (1) - (2)), the additional auxiliary screen and the inductor with the exciting current is staying invariable. The review of the patented tools for the non-magnetic metals magnetic pulsed attraction is divided on two main blocks: ISAS of the cylindrical geometry and ISAS of the rectangular geometry. A physical difference between the marked out constructions shapes consists in the following: in the cylindrical ISAS the induced currents have the circular flowing ways but in the rectangular ISAS they are flowing along the rectilinear trajectories. Taking into account these factors the induced currents densities distribution and the excited fields' concentration in the tools working zones can be varied.

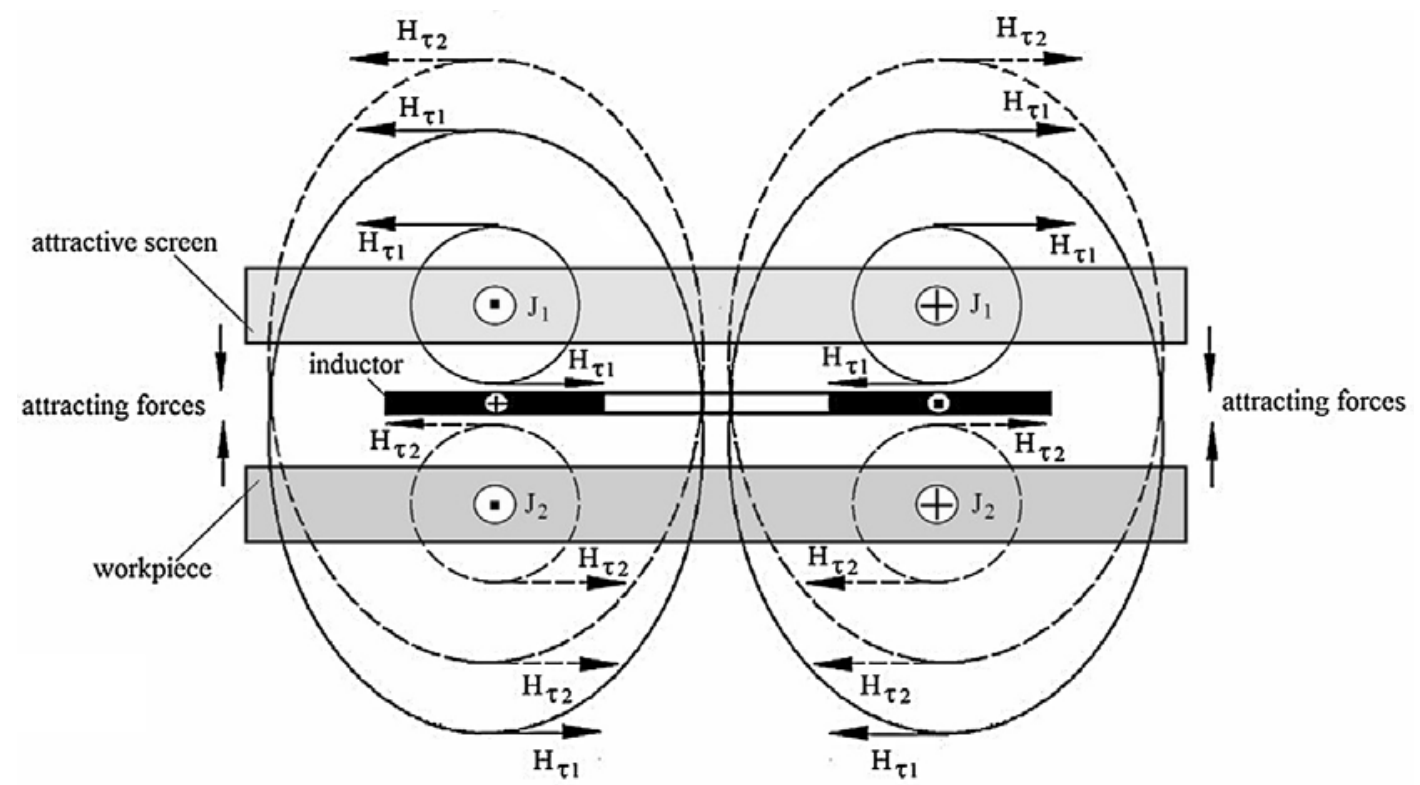

Fig. 4. Schematic illustration of the physical processes in ISAS, $\mathrm{J}_{1,2}-$ the unidirectional currents induced in the screen and in the blank, $\mathrm{H}_{\tau 1,2}$ - the tangential components of the magnetic field intensity being excited by the currents $\mathrm{J}_{1,2}$

«Inductor Systems with Attracting Screens» cylindrical constructions. Placing the single-turn inductor in the slot of the screen with finite thickness from side of the billet which is being processed is suggested in [18]. The present construction modification demands the working frequency limitation by the least value from:

$$
f<<\frac{1}{\pi \cdot D^{2} \cdot \mu_{0} \cdot \gamma_{s}} \text { or } f<<\frac{1}{\pi \cdot d^{2} \cdot \mu_{0} \cdot \gamma_{b}},
$$

where $D, d-$ the thicknesses of the screen and billet accordingly, $\gamma_{s}, \gamma_{b}-$ the specific conductivity of the screen and billet accordingly.

The aim of [19] consists in increasing the acting field amplitudes. The authors suggested the circular inductor which has to be made of two separate concentric rings with two opposite slits along the diameter axis. The rings have to be connected in such a way as to provide unidirectional currents in the inner turns of ring at connection of the inductor to a power source. A novelty of [20] consists in a possible choice of the screen geometry. Its thickness remains the same along the cross section and can be defined from inequality: $d_{s}<<\Delta$, where $\Delta-$ a skin layer value. A method of pulsed magnetic attraction of metal objects by a double-coil circular inductor system and with a thin screen is represented in [21 - 23]. The difference of the cited Patents is the difference of the coils constructive fulfilling. The essential novelty being suggested consists in what inductor is designed as two flat coils. One of them is placed under the screen from the billet side. The second is situated above the screen. Current in the coils flows in one direction. The excited fields are summed. As in the previous patent the thickness of the auxiliary screen is chosen the same along all cross section. Unlike to the previous suggestions, in [24, 25] the inductor represented by the single-turn [24] or multi-turn flat coil [25] is placed on the external surface of the auxiliary screen. This solution permits weakening the repelling Lorentz forces between the current induced in the billet metal and the current in inductor. It occurs because of screening them each of other by the conducting auxiliary screen. Besides of that the external placing the inductor coil allows constructively to increase the strength of the attraction tool in whole. The last what can be added as advantage this is a possibility to place all construction including the inductor winding and auxiliary screen in a closed body. The scheme of the most successful ISAS construction [25] given on Fig. 5.

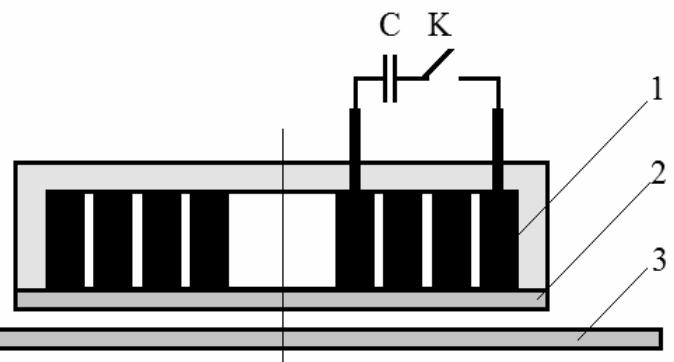

Fig. 5. Schematic representation of ISAS with the external flat multi-turn winding of inductor, 1 - the winding; 2 - the screen; 3 - the sheet billet

Speaking about applications it should be noted the present attraction tool can be very comfortable for exter- 
nal non-contact straightening a body of car or aircraft (without disassembly) and as well in machine building where processing a blank can be done only from one side.

«Inductor Systems with Attracting Screens» rectangular constructions. The main difference of the below represented inventions from before suggested cylindrical constructions consists in the rectangular form of the inductors used as the magnetic field generators. The demanded frequencies from [18] are the same to [26], but the inductor placed between the screen and billet is already made in the shape of two coplanar loops of rectangular form electrically connected in series to each other. Their current-conductors limiting the working area are parallel. A single-turn rectangular inductor placed between the screen and billet which has two cuts along the axis of symmetry and which divide it into two separate branches, in series or parallel connection of which to each other is patented [27]. This construction allows adjusting

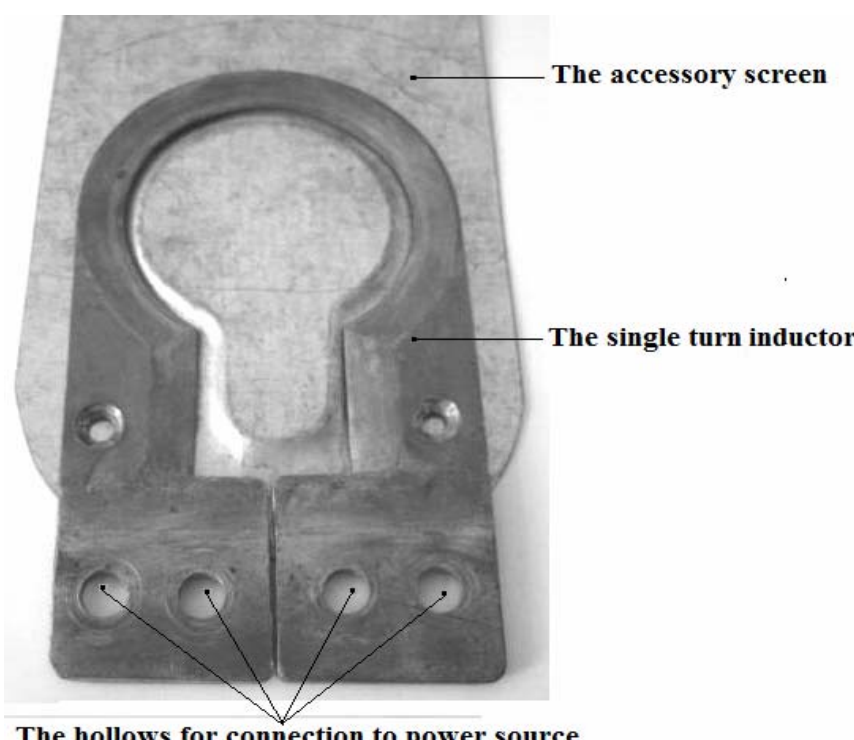

The hollows for connection to power source $a$

The rectangular inductor with two parallel inner branches

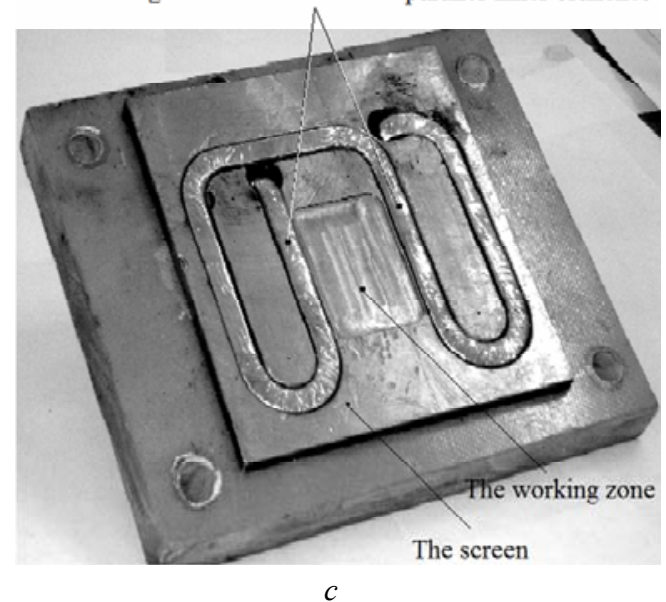

inductance of the inductor and amplitude of exciting fields in dependence on the above mentioned separate branches connection view. The suggestion in [28] is identical to the patented suggestion in $[21-23]$. The main difference and essential novelty consists in what inductor is designed as two single-turn flat rectangular coils. But the same as in [21 - 23] one of them is placed under the screen from the billet side. The second is situated above the screen. Current in the coils flows in one direction. The excited fields are summed. The last variation of the inductor geometrical form (in comparison with solution in [24]) is patented by authors [28]. Unlike previous claims with rectangular inductors this suggestion consists in placing the rectangular single-turn inductor not between the screen and sheet billet but fully above the auxiliary screen. For visual imagine the above described constructions of the inductor systems for the sheet billets attraction are given below on Fig. 6.
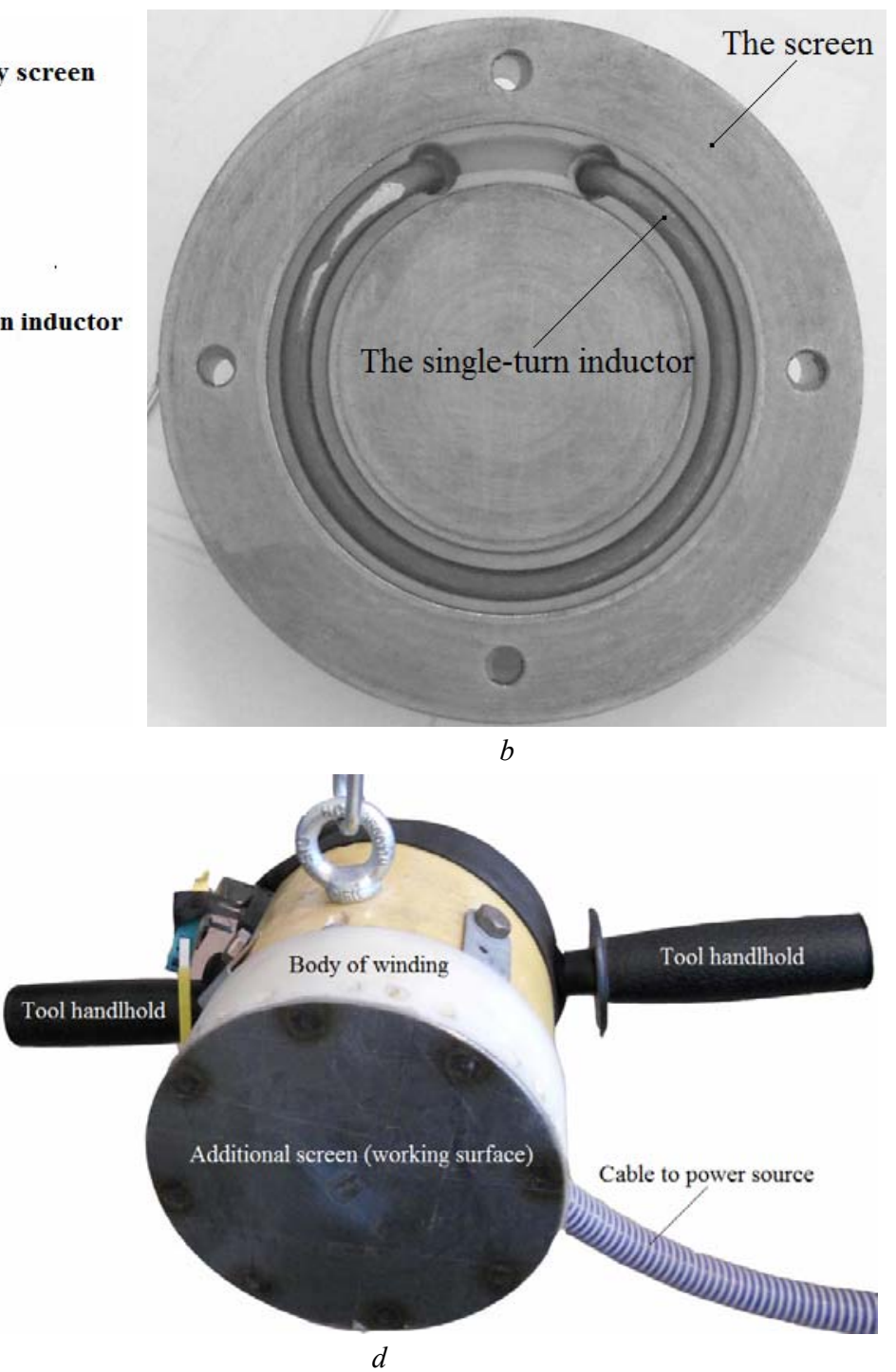

Fig. 6. Experimental models of «Inductor Systems with Attracting Screen», a) the first construction for experiments; $b$ ) the circular single-turn inductor in depression on a screen surface; $c$ ) the rectangular inductor with two inner parallel branches; $d$ ) the construction with the external flat multi-turn winding in assembly

Generalizing of the represented inventions of the «Inductor Systems with Attracting Screens» as the tools for work with the thin-walled metals it should be added that all described constructions were tested in experiments which affirmed their workability. Some results of the ISAS experimental testing are represented on Fig. 7. 


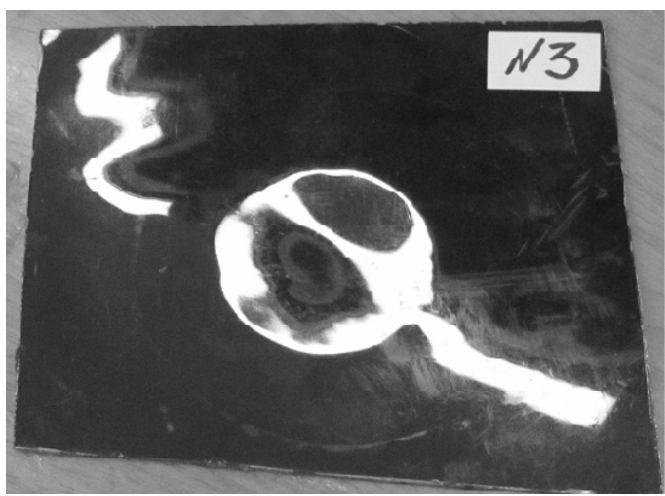

$a$

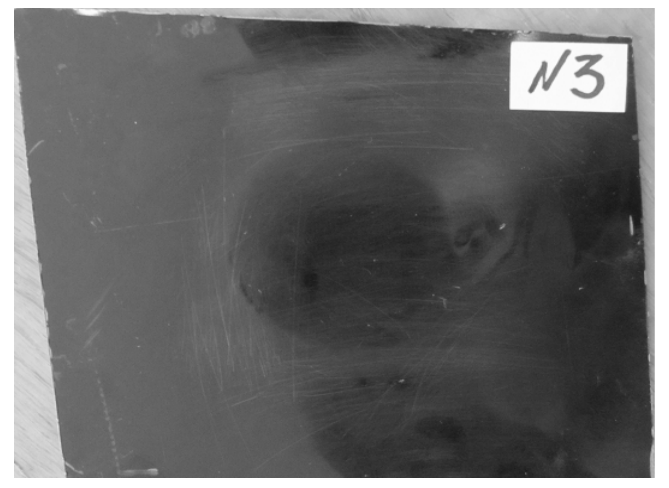

$b$

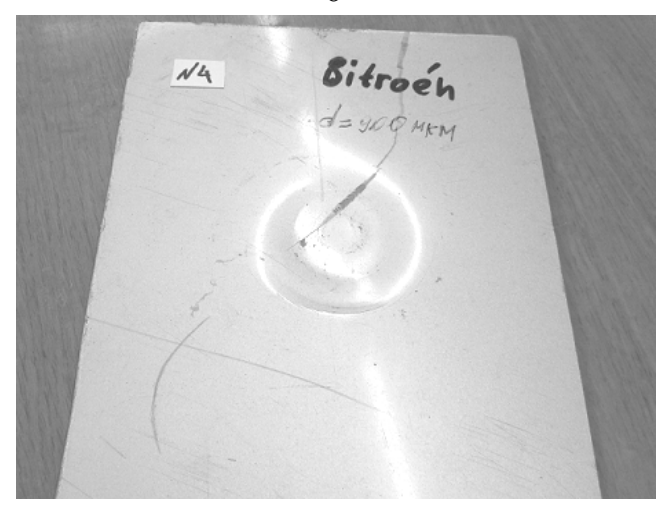

$c$

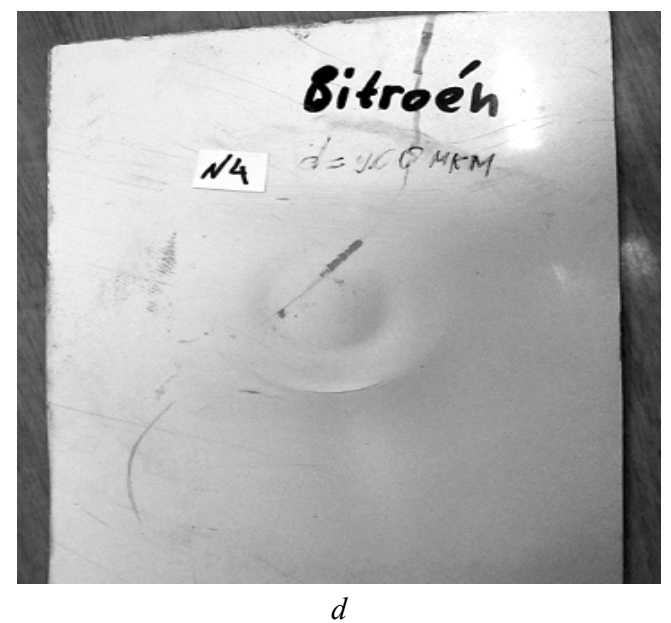

Fig. 7. The experimental samples from different automotive steels, «Subaru»: $a$ - before the power action, $b$ - after attraction; «Citroen»: $c$ - before the power action, $d$ - after attraction

The magnetic-pulsed installation as the power source in the equipment for the metal sheets attraction. The experimental investigations were conducted on the magnetic-pulsed installation - MPIS-2 created in Laboratory of Electromagnetic Technology of the Kharkov National Automobile \& Highway University (Fig. 8) and used as the power source with stored energy $\sim 2 \mathrm{~kJ}$ under maximal voltage $\sim 2200 \mathrm{~V}$ and own frequency $\sim 7.5 \mathrm{kHz}$.

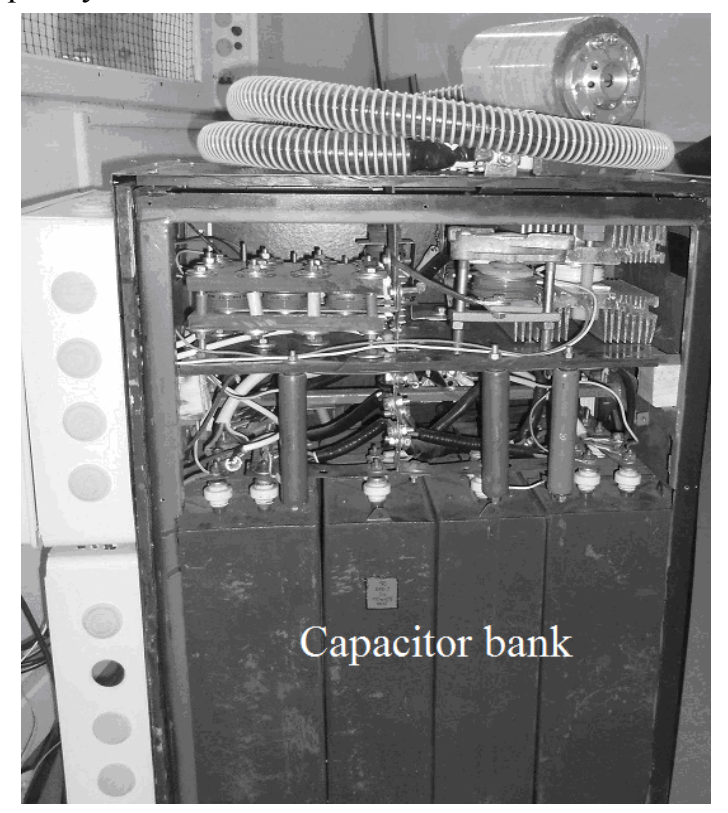

$a$

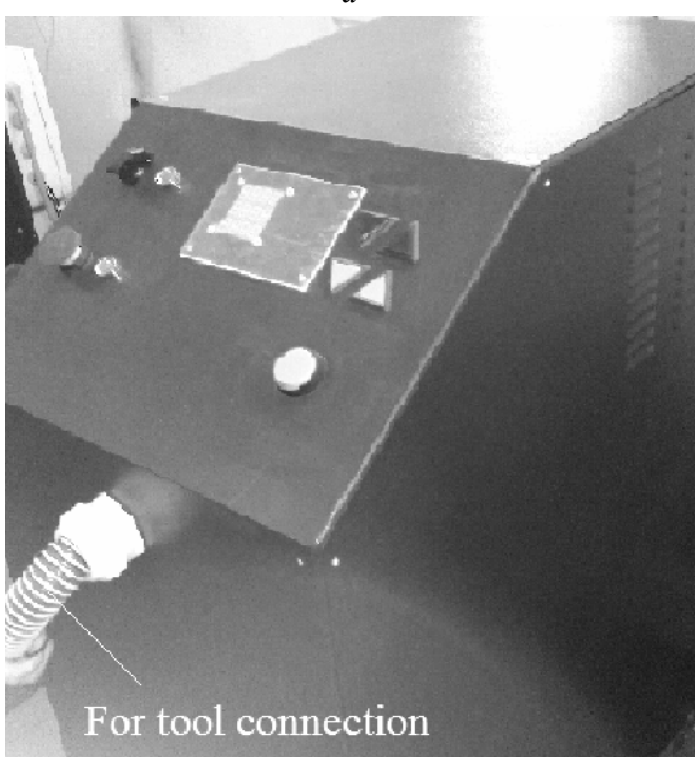
b

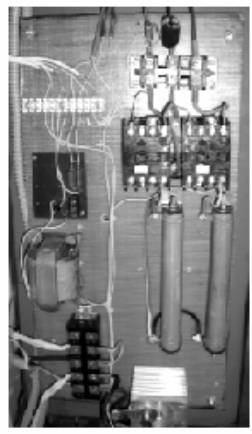

$c$

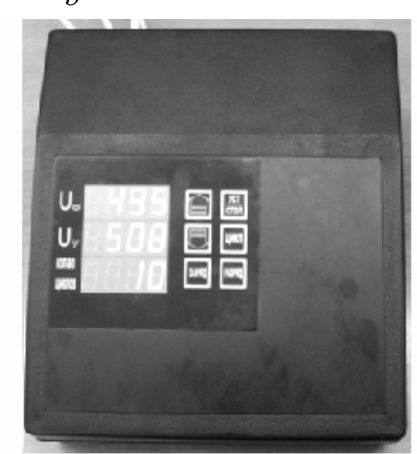

$d$
Fig. 8. The main components of MPIS $-2, a$ ) the inner arrangement; $b$ ) the external view; $c$ ) the control block; d) the remote control panel 
Not stopping on the known components of the power source in equipment for the MPMW let us point out the main feature of the represented magnetic-pulsed installation is a work in regime automatically repeating force action pulses with repetition preset frequency (till $\sim 10 \mathrm{~Hz}$ ). The present regime is provided by introduction of the thyristor synchronizing device in the installation electrical scheme [29]. It should be noted the further increasing the repetition frequency of the force action pulses is limited by possibilities of the industrial network. In [30] the patented suggestion consists in usage of the capacitive energy storage special type that is named as «ionistor». Usage of ionistor instead of the traditional capacitive energy storage allows essential decreasing the working voltages without decreasing the working currents what leads to decreasing the power source cost eventually in whole. As it is known the natural discharge of capacitor in an electrical circuit with inductance and resistor has to have the harmonic temporal form for minimum energy losses. But the current and voltage oscillations are decreasing a life cycle the capacitive energy storage. Besides, as it turned out from practice the thyristor commutators in the installation control scheme cannot work in this temporal regime. By this reasons the aperiodic or unipolar temporal form of discharge is more preferential. The problem forming unipolar pulses with minimum energy losses in the discharging circuit is solved by authors [31]. Very interesting scheme of the charging block is patented in [32]. The suggestion essence is based on so named «step-by-step charge» of the capacitive energy storage bank by the serial pulses of the equal energy. This scheme permits excepting the step-up transformer from the charging block and decreasing a cost of the installation in the whole.

The magnetic-pulsed attraction of sheet metals for dents removing on the body car surfaces. The patents [25] and [33] are dedicated to the practical applications of the magnetic pulsed attraction of thin-walled metals. In the [25] the most effective magnetic-pulsed tool of attraction is described (it was represented before as ISAS). Should remind this inductor-tool to remove dents on the surface of the object being processed is fulfilled as a complicated system consisting of the multiturn coil which plays the role of matching transformer and auxiliary attracting screen. The coil is placed on the external surface of the screen. Its opposite inner surface is the tool working surface from side of which the dent in sheet metal is being located. Undoubted advantage of this tool construction is essential decreasing the repelling Lorentz forces at expense of remoting the coil current from the current induced in the sheet metal being processed. In [33] the full complex (Fig. 9) of the external non-contact magnetic-pulsed flattening is represented which includes and the tool and the electromagnetic power source.

In main the equipment for the external magnetic pulsed straightening unites previously described and patented components. A detailed description of such complexes is showed in «The complex of the external magnetic pulsed straightening» [25]. The complex contents a remote portable tool allowing processing any demanded parts of the sheets with dents. The magnetic-pulsed installations are being connected to the inductor-tool by flexible cable. If the tool for ferromagnetics attraction is being used then this connection fulfils through the matching transformer. The charging and discharging circuits are connected through the thyristor-electronic device which synchronizes the work of these circuits. Their interconnection determines the resistor value for limitation of the charging current which provides the installation functionality in the whole:

$$
R_{c h} \gg 2 \delta_{0} \cdot \sqrt{\frac{L_{\text {disch }}}{C}},
$$

where $R_{c h}$ - the resistor in the charging circuit, $\delta_{0}$ and $L_{\text {disch }}$ - the relative damping decrement and the integral inductance of the discharging circuit.

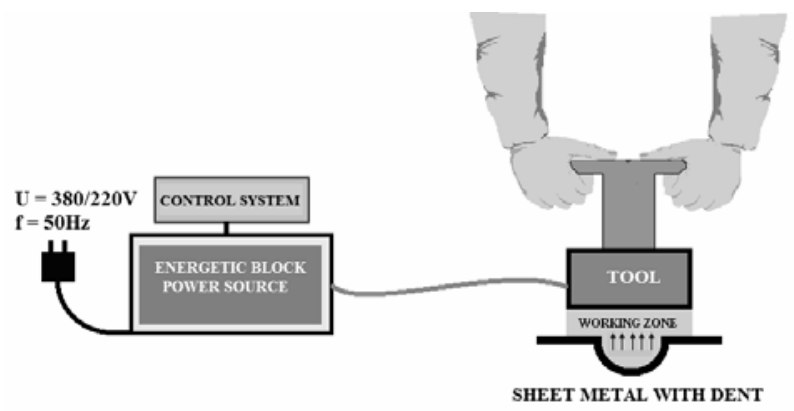

Fig. 9. Schematic illustration of magnetic-pulsed removing the dents in the sheet metal

The discharging circuit of the magnetic-pulsed installation can be represented by several parallel branches which consist of the same capacitors and synchronized thyristor commutators with a common exit to the inductor-tool. Their quantity has to provide the normal work conditions of all power electronics devices. The «ionistor» can be used as the energy storage in the magnetic pulsed installation. But its including in the working scheme demands reforming of the charging and discharging circuits accordingly to the nomenclatorial characteristics of the concrete «ionistor». The discharging circuit has to contain the system for transformation the natural harmonic temporal form of the discharging current pulses to the aperiodic one. This can be the bridge circuit or the well known from the Electrical Engineering «a crowbar circuit». The own frequency of the magnetic pulsed installation is being determined by its parameters and is fixed value. That is why the integral characteristics of the power action tools (with the matching transformer or without this component in the charging circuit) have to be chosen by such way in order to provide the needed working frequency of the fields being excited. The constructions of the inductor-tools, its parameters (independently on the principle action) and its location place on the sheet metal being processed have to be chosen so in order to the high effectiveness providing the dents removing operation according to all previous recommends. Should add that place location of any inductor system has to provide the best electrodynamical tie between the sheet metal being processed and the dent removing tool. In conclusion of the present consideration some documental illustration of the practical magnetic pulsed removing the dents by the flattening complex are represented. The first photographs (Fig. 10) illuminate the repair technology of the automobile «Audi» door by the tool «Inductor System with Attracting Screen».

The next photos (Fig. 11) illustrate a technological route as algorithm of the dent removing on the automobile «Subaru» door. 


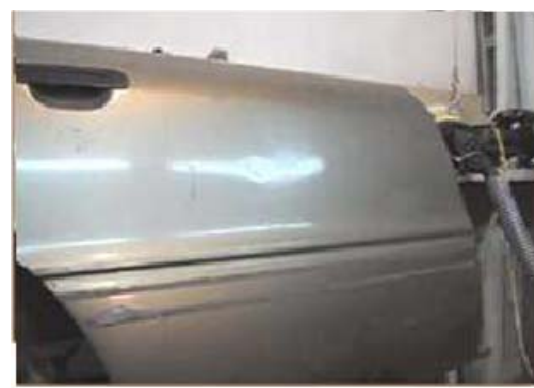

$a$

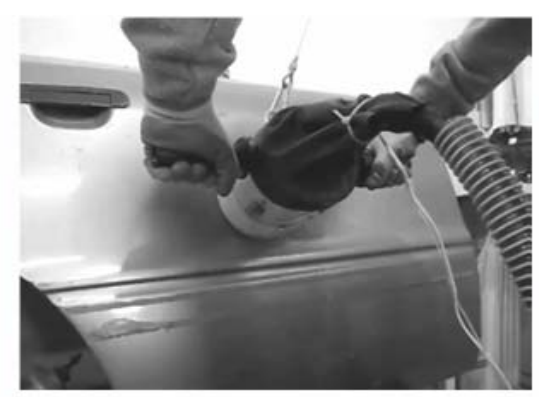

$b$

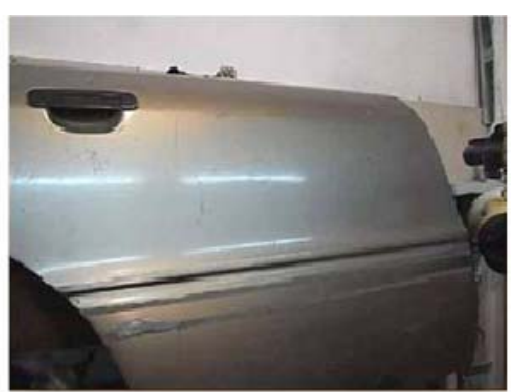

$c$

Fig. 10. The external EMF flattening in the real repair process, $a$ ) the door before flattening; $b$ ) the tool ISAS in action; $c$ ) the door after flattening

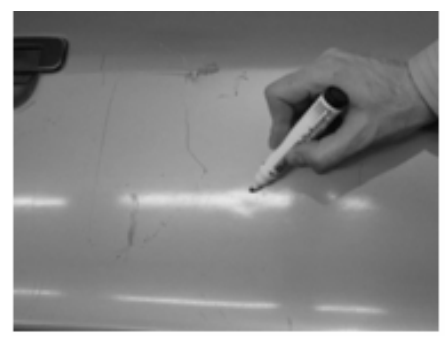

$a$

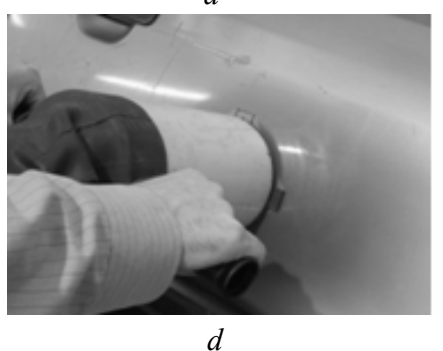

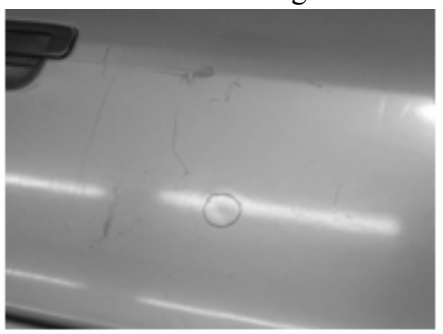

$b$

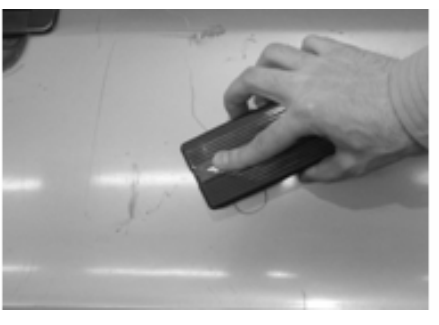

$e$

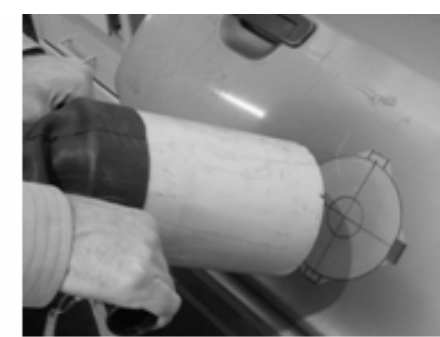

$c$

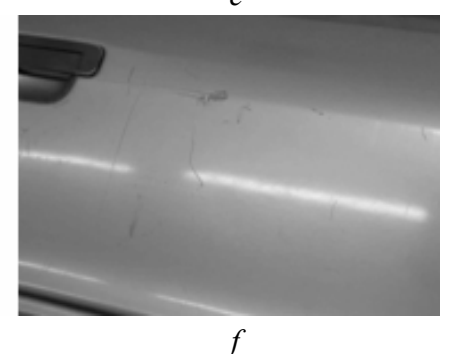

Fig. 11. Photo-illustrations of the technological route, $a$ ) determination of the dent; $b$ ) marking the boundary dimensions;

c) fixing the tool over the dent; $d$ ) the magnetic pulsed action; $e$ ) the marker removing; $f$ ) the car door panel after the flattening

Technological process. It should be noted that during the experiments of the magnetic-pulsed removing the dents there were approbated many samples steel coverings of the bodies European and Japanese cars. Visual car body parts surface inspection in order to determine a dent to be removed (Fig. 11,a). The geometrical dimensions and nature of this dent determine the level and intensity of the required force action. A special dielectric insert is placed on the car panel element over the dent. Its purpose consists in fixation of the tool working area toward to the external boundaries of the dent to be removed (Fig. 11,c). The necessary energy level and the pulses quantity are set by the operator on the control panel (Fig. 11,d). The operator places the tool working surface above the dent area (Fig. 11,d). The operator turns the system on and implements an external non-contact flattening (Fig. 11,e). The excited forces attract metal of the dent to the surface needed level. After flattening the tool and the insert are taken away and the surface is cleaned up (Fig. 11,f). If it is necessary, technological process is repeated few times, till the complete damage removing. In the case, when the dent has big enough size another approach may be used. It consists in its gradual removing. The process should be begun from the edges of the dent and move to its centre.

Conclusions. The fundamental inventions in the field of the Magnetic Pulsed Attraction of the sheet metals using low frequency discharges are illuminated. The most part of them is defended by the Ukrainian Patents and little known to the west specialists in the area of the magnetic pulsed technologies.

The different types of the attracting tools based on different physical principles and attended for work with metals owning by different electrophysical properties are represented. They can deform the ferromagnetics such as low carbon steels and the non-magnetic metals such as alloys of aluminum for example.

The novelties in the magnetic pulsed installations used as the power sources in the complex equipment for the automobile bodies repair are given. The practical application of the elaborated systems for the dents removing in the sheet metals are suggested and successfully approbated.

In the whole these works can be considered as new scientific direction and used for different manufacturing aims though the main attention is paid to the practical application in the field of the automobile bodies repair.

\section{REFERENCES}

1. Psyk V., Risch D., Kinsey B.L., Tekkaya A.E., Kleiner M. Electromagnetic forming - A review. Journal of Materials Processing Technology, 2011, vol.211, no.5, pp.787-829. doi: 10.1016/j.jmatprotec.2010.12.012.

2. Furth H. et al. Devices for metal-forming by magnetic tension. US Patent, no.3,196,649, 1965.

3. Karl A. Hansen, Iver Glen Hendrickson. Electromagnetic dent puller. US Patent, no.3,998,081, 1976.

4. I. Glen Hendrickson, Karl A. Hansen. Electromagnetic dent remover with tapped work coil. US Patent, no.4,986,102, 1991.

5. Peter B. Zieve. Power supply for electromagnetic proof load tester and dent remover. US Patent, no.5,046,345, 1991.

6. Available at: http://www.electroimpact.com (accessed 15 January 2018).

7. Available at: http://www.fluxtronic.com (accessed 15 January 2018).

8. Shneerson G.A. Polya $i$ perehodnye processy $v$ apparature sverhsilnyh tokov [Fields and transients in equipment superstrong currents]. Leningrad, Energoizdat Publ., 1981. 200 p. (Rus). 
9. Batygin Yu.V., Lavinsky V.I., Khimenko L.T. Direction Change of the Force Action upon Conductor under Frequency Variation of the Acting magnetic Field. Proceedings of the $1^{s t}$ International Conference on High Speed Metal Forming. March 31/April 1, 2004. Dortmund, Germany, pp. 157-160.

10. Batygin Yu.V., Lavinskiy V.I. Khavin V.L., Khimenko L.T. Sposib magnitno-impul'snoi' obrobky tonkostinnyh metalevyh zagotovok [Method of magnetic-pulse working of thin-walled metallic billets]. Patent UA, no.75676, 2006.

11. Meichtry R., Kouba I. International Patent Application, no.2006119661, 2006.

12. Meichtry R., Basler B., Kouba I. International Patent Application, no.20160044748, 2016.

13. Available at: http://www.betaginnovation.com (accessed 15 January 2018).

14. Argun Sh.V., Batygin Yu.V., Gnatov A.V., Smirnov D.O., Trunova I.S., Chaplygin Ye.A., Shchigoleva S.A. Sposib magnitno-impul'snoi' obrobky tonkostinnyh metalevyh zagotivok z vykorystannjam uzgodzhuval'nogo prystroju [The method of magnetic pulsed processing of thin-walled metal billets with using a matching device]. Patent UA, no.69467, 2013.

15. Argun Sh.V., Batygin Yu.V., Gnatov A.V., Trunova I.S., Chaplygin Ye.A. Sposib magnitno-impul'snoi' obrobky tonkostinnyh metalevyh zagotovok [The method of magnetic pulsed processing of thin-walled metal billets]. Patent UA, no.68745, 2011.

16. Argun Sh.V., Batygin Yu.V., Gnatov A.V., Trunova I.S., Chaplygin Ye.A., Shchigoleva S.A. Sposib magnitnoimpul'snogo prytjagannja metalevyh ob'jektiv sumishhenym dyskovym pogodzhuval'nym prystrojem z dempfernoju konstrukcijeju [The method of magnetic pulsed processing of the metal objects by integrated matching disk device with a damping construction]. Patent UA, no.75790, 2012.

17. Batygin Yu.V., Lavins'kij V.I., Khavin V.L. Sposib magnitno-impul'snoyi obrobki tonkostinnih metalevih zagotovok [Method of the magnetic-pulse processing thin metal work pieces]. Patent UA, no.74909, 2006.

18. Chaplygin Ye.A., Batygin Yu.V., Bondarenko A.Yu. Sposib magnitno-impul'snoi' obrobky metalevyh zagotivok metodom prytjagannja do induktora [Method of magnetic-pulse working of metallic billets by attraction to inductor]. Patent UA, no.31751, 2008.

19. Batygin Yu.V., Gnatov A.V., Chaplygin Ye.A., Smirnov D.O. Sposib magnitno-impul'snogo prytjagannja metalevyh ob'jektiv odnovytkovym cylindrychnym induktorom, rozdilenym na dvi gilky [Method of magnetic pulse attraction of metal objects by two-wind cylindrical inductor divided into two branches]. Patent UA, no.54753, 2010.

20. Batygin Yu.V., Gnatov A.V., Argun Sch.V., Chaplygin Ye.A., Gopko A.V., Drobinin A.M. Sposib magnitnoimpul'snogo prytjagannja metalevyh ob'jektiv odnovytkovoju induktornoju systemoju z tonkym ekranom [Method of pulsed magnetic attraction of metal objects by single-turn inductor system with thin screen]. Patent UA, no.70055, 2012.

21. Batygin Yu.V., Gnatov A.V., Shigoleva S.A., Chaplygin Ye.A., Gopko A.V., Drobinin A.M. Sposib magnitnoimpul'snogo prytjagannja metalevyh ob'jektiv dvovytkovoju krugovoju induktornoju systemoju $z$ tonkym ekranom [The method of magnetic-pulse attraction of metal objects by doubleturn circular inductor system with a thin screen]. Patent UA, no.70734, 2012.

22. Batygin Yu.V., Gnatov A.V., Chaplygin Ye.A., Shinderuk S.A., Sabokar O.S. Sposib magnitno-impul'snogo prytjagannja tonkostinnyh lystovyh metaliv bagatovytkovoju krugovoju indukcijnoju induktornoju systemoju [The method of pulsed magnetic attraction of thin sheet metals by induction multiturn rotary inductor system]. Patent UA, no.92037, 2014.

23. Batygin Yu.V., Gnatov A.V., Chaplygin Ye.A, Shinderuk S.A., Sabokar O.S. Bagatovytkova krugova indukcijna induk- torna systema dlja magnitno-impul'snogo prytjagannja tonkostinnyh lystovyh metaliv [The multiturn rotary induction coil system for pulsed magnetic attraction of thin sheet metals]. Patent UA, no.92436, 2014.

24. Batygin Yu.V., Gnatov A.V., Chaplygin Ye.A., Trunova I.S., Gopko A.V., Sabokar O.S. Sposib magnitno-impul'snogo prityagannya metalevih zagotivok odnovitkovim krugovim induktorom, roztashovanim nad dopomizhnim ekranom [Method of the magnetic-pulse attraction metal workpeaces single-turn circular inductor located on the auxiliary screen]. Patent UA, no.77579, 2013.

25. Batygin Yu.V., Gnatov A.V., Chaplygin Ye.A, Sabokar O.S. Sposib magnitno-impul'snoi' obrobky poverhon' kuzovnyh elementiv [The method of magnetic pulsed processing surface body elements]. Patent UA, no.104509, 2015.

26. Batygin Yu.V., Bondarenko A.Yu., Serikov G.S. Sposib magnitno-impul'snoi' obrobky metalevyh zagotivok [Method of magnetic-pulse working of metallic billets]. Patent UA, no. 31752,2008

27. Batygin Yu.V., Gnatov A.V., Serikov G.S., Drachenko S.A. Sposib magnitno-impul'snogo prytjagannja metalevyh ob'jektiv prjamokutnym induktorom, $z$ dvoma rozrizamy [Method of magnetic pulse attraction of metal objects by rectangular inductor with two slots]. Patent UA, no.53968, 2010.

28. Batygin Yu.V., Gnatov A.V., Chaplygin Ye.A., Shinderuk S.A., Shchigoleva S.A., Sabokar O.S. Sposib magnitnoimpul'snogo prytjagannja metalevyh zagotivok induktornoju systemoju $z$ dvoma prjamokutnymy vytkamy ta tonkym ekranom [The method of the magnetic pulsed attraction of the metallic billets by the inductor system with two rectangular turns and by the thin screen]. Patent UA, no.78243, 2013.

29. Batygin Yu.V., Bondarenko A.Yu., Gnatov A.V., Serikov G.S., Chaplygin Ye.A. Generator bagatorazovyh impul'siv strumu dlja magnitno-impul'snoi' obrobky metaliv [Generator of repeated current pulses for magnetic pulse working metals]. Patent UA, no.44933, 2009.

30. Batygin Yu.V., Gnatov A.V., Chaplygin Ye.A., Gnatova Sh.V., Trunova I.S. Generator bagatokratnyh impul'siv strumu dlja obrobky metaliv tyskom impul'snogo magnitnogo polja [Generator of multiple pulses of current for metal forming by pulsed magnetic field pressure]. Patent UA, no.61417, 2011.

31. Batygin Yu.V., Gnatov A.V., Chaplygin Ye.A., Dzubenko A.A., Argun Sh.V., Drobinin A.M. Generator bagatorazovyh unipoljarnyh impul'siv strumu dlja magnitno-impul'snoi' obrobky metaliv [The generator of multiple unipolar current pulses for magnetic-pulse metal working]. Patent UA, no.73733, 2012.

32. Batygin Yu.V., Chaplygin Ye.A., Sabokar O.S. Peretvorjuvach energii' zarjadnogo konturu magnitno-impul'snoi' ustanovky [The energy transducer for the magnetic pulsed installation charging circuit]. Patent UA, no.110809, 2016.

33. Batygin Yu.V., Gnatov A.V., Chaplygin Ye.A., Argun Sh.V., Shinderuk S.A., Sabokar O.S. Kompleks zovnishn'ogo magnitno-impul'snogo ryhtuvannja [The complex of the external magnetic pulsed straightening]. Patent UA, no.101413, 2015.

Received 06.02.2018

Yu.V. Batygin ${ }^{1}$, Doctor of Technical Sciences, Professor,

E.A. Chaplygin ${ }^{1}$, Candidate of Technical Sciences, Associate Professor,

S.A. Shinderuk ${ }^{1}$, Candidate of Technical Sciences, Associate Professor

V.A. Strelnikova ${ }^{1}$, Postgraduate Student,

${ }^{1}$ Kharkiv National Automobile and Highway University, 25, Yaroslava Mudrogo Str., Kharkov, 61002, Ukraine, e-mail: yu.v.batygin@gmail.com; chaplygin.e.a@gmail.com; s.shinderuk.2016102@ukr.net; v.strelnikova91@gmail.com

How to cite this article:

Batygin Yu.V., Chaplygin E.A., Shinderuk S.A., Strelnikova V.A. The main inventions for technologies of the magneticpulsed attraction of the sheet metals. A brief review. Electrical engineering \& electromechanics, 2018, no.3, pp. 43-52. doi: 10.20998/2074-272X.2018.3.06. 